\title{
Anti-tumoral activity of lipophilic Eucalyptus bark extracts, enriched on triterpenic acids, against breast cancer cells
}

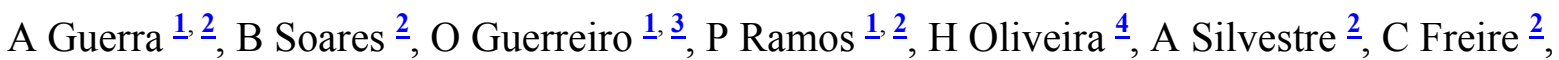
MF Duarte 1

- ${ }^{1}$ Centro de Biotecnologia Agrícola e Agro-Alimentar do Alentejo (CEBAL)/Instituto Politécnico de Beja (IPBeja), 7801 - 908 Beja, Portugal

- $\quad{ }^{2}$ CICECO \& Department of Chemistry, University of Aveiro, Campus de Santiago, 3810 - 193 Aveiro, Portugal

- $\quad{ }^{3}$ CIISA, Centro de Investigação Interdisciplinar em Saúde Animal, Faculdade de Medicina Veterinária, Pólo Universitário do Alto da Ajuda, 1300 - 477 Lisboa, Portugal

- ${ }^{4}$ CESAM \& Department of Biology, Laboratory of Biotechnology and Cytometry, University of Aveiro, 3810 - 193 Aveiro, Portugal

The agro-industrial exploitation of eucalyptus for pulp production generates large amounts of biomass residues, particularly bark. Eucalyptus spp. is the most important fiber source for pulp and paper production in southwestern Europe [1]. 

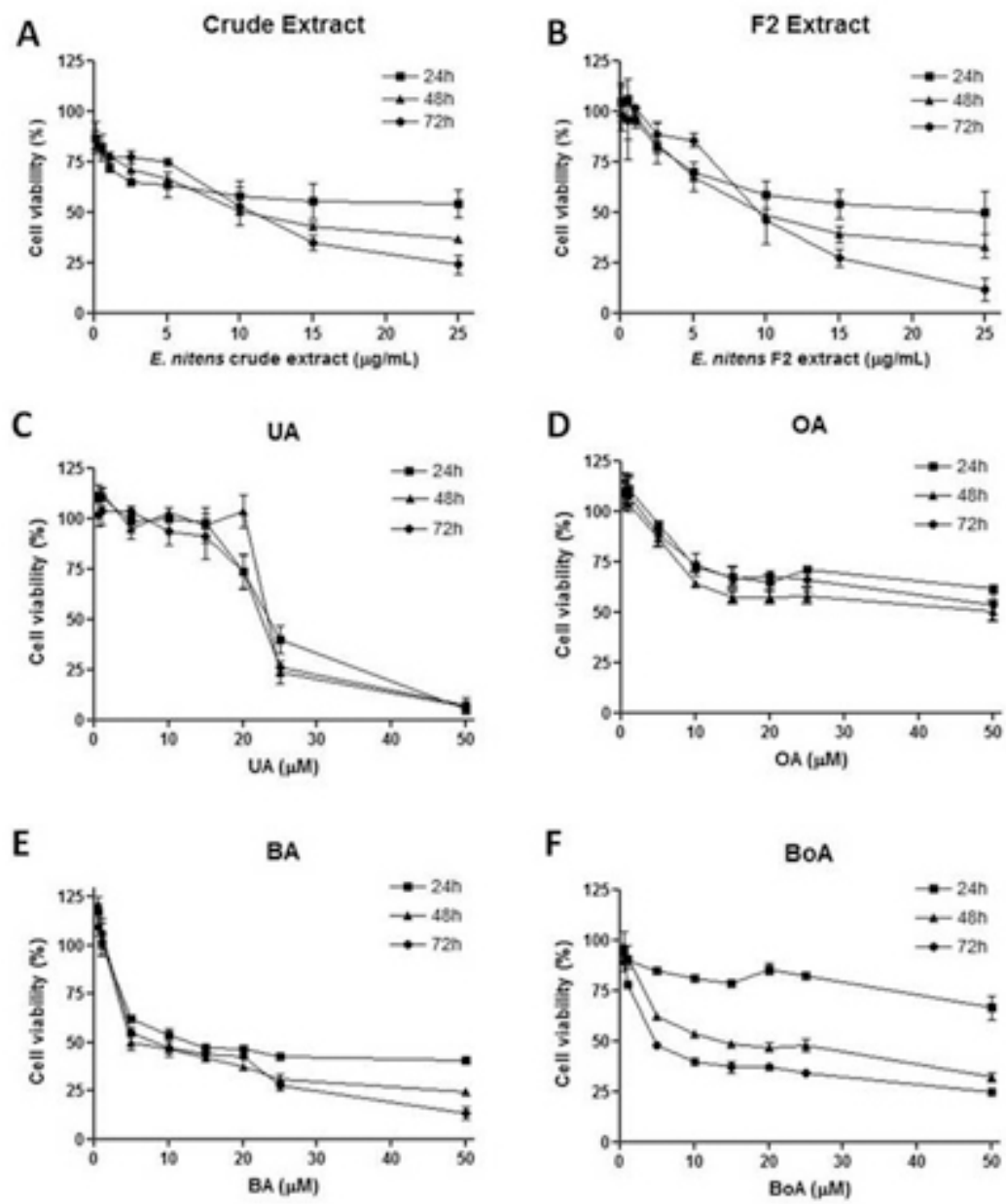

Fig. 1: Antiproliferative effect of Eucalyptus ritens Crude, F2 extracts and triterpenic acids on human breast cancer cells. Dose-response curves of E. nitens Crude (A) and F2 (B) extracts and UA (C), OA (D), BA (E) and BoA (F) treatment in MDA-MB-231 cells.

Eucalyptus spp. barks are an abundant source of several triterpenoids, mostly triterpenic acids (TAs), namely betulinic (BA), oleanolic (OA), ursolic (UA) and betulonic (BOA) acids [2]. These pentacyclic triterpenes have a broad spectrum of biological activities, being some of them considered promising anticancer drugs [3]. Therefore, the present work aims to characterize the anti-tumoral activity of pure TAs (UA, OA, BA and BOA) as well as total and fractionated (enriched on different TAs) Eucalyptus nitens outer bark derived extracts, in a breast cancer in vitro cell model. The crude and fractionated $E$. nitens outer bark extracts were previously chemically characterized [2]. Crude and Fractionated (F2) extracts inhibited the proliferation of MDA-MB-231 cells in a dose- and time-dependent manner. Treatment of MDA-MB-231 cells with crude and F2 extracts resulted in a significant reduction in cell migration, as compared to vehicle control. Cell cycle analysis was also assessed by flow cytometry. Since the phosphatidylinositol 3-kinase(PI3K)/Akt is the signalling pathway frequently implicated in oncogenic transformation in breast cancer, the phosphor-Akt protein levels were also determined. Taken together, our study suggests potential therapeutic effect of Eucalyptus spp. bark extracts against an aggressive breast cancer cell model.

\section{References:}

[1] Rencoret, J., et al (2007) Holzforschung, 61:165 - 174. 
[2] Domingues, R., et al (2011) Cellulose Chem. Technol., 45: 475 - 481.

[3] Domingues, R. M. A., et al (in press) Mini-Rev Org Chem. 